\title{
Arbor
}

\section{Un comunitarismo radical: el fundamentalismo islámico}

Eduardo Ruiz Abellán

Arbor CLXV, 652 (Abril 2000), 759-780 pp.

El Fundamentalismo islámico se presenta en nuestros días como una amenaza al mundo Occidental que, en cierta medida, viene a sustituir el enfrentamiento bipolar típico del mundo durante la «Guerra Fría». Junto a factores ideológicos, sociales y económicos que explican la reacción de sectores cada vez más numerosos del mundo islámico ante el fracaso de las ideologías modernizadoras, también encontramos aspectos míticos que tratan de mantener la cohesión social frente a la amenaza exterior en el mundo occidental.

El comunitarismo es una corriente de pensamiento cuyos inicios pueden situarse en Estados Unidos a partir de los debates morales y políticos que surgen en el mundo anglosajón como reacción ante los excesos de las políticas neoliberales llevadas a cabo por la Administración Reagan y por la Primera Ministra Margaret Thatcher.

En un sentido más amplio y, en cierta medida, más profundo, el comunitarismo entronca con la gran crítica a la Modernidad y ello en la medida en que al defender el comunitarismo el resurgir de las comunidades básicas, entre ellas, la familia, favorece los factores de socialización y de solidaridad, frente a las posiciones de la teoría neoclásica que priman una visión de la sociedad como fruto de la articulación contractual entre individuos aislados.

En una síntesis apresurada, se podría decir que el comunitarismo intenta aunar la ética de lo colectivo con la dinámica del mercado en un in- 
tento de volver a soldar un tejido social en el que la implementación de las políticas liberales de los años setenta y ochenta produjo graves desgarros $^{1}$.

A la modernidad se la acusa, en definitiva, de haber promovido un modelo de sociedad de corte hobbesiano en el que el Estado no sería mas que una construcción artificial de la razón frente a un modelo aristotélico anterior que vería la sociedad política como la culminación de un proceso a partir de formas más primitivas de sociabilidad ${ }^{2}$. Nos encontramos, por tanto, ante una reivindicación de los grupos primarios en tanto que grupos de dimensiones reducidas pero capaces de desarrollar sus propias normas y costumbres y en los que la interacción es intensa y directa. Estamos en la antítesis del proyecto moderno, que, en la medida en que trate de hacerse realidad, supone la disolución de los lazos comunitarios en beneficio de modos de relación de carácter contractual ${ }^{3}$.

A tenor de lo ya indicado, es evidente que no nos encontramos ante un mero debate de tipo especulativo, sino ante el intento de encontrar solución a los problemas planteados por la crisis de la modernidad, crisis que reviste en todas las sociedades periféricas un carácter devastador y que en las sociedades musulmanas asume una agudeza ideológica particular aún más grande. Y es que como afirma B. Ghalioun: la modernización tecnocrática, en tanto que proyecto intentado para lograr el desarrollo de los pueblos del Sur, es considerada como inhumana e injusta: «por doquier en el Tercer Mundo, allí donde se ha impuesto la modernidad, la sociedad se ha dividido en dos comunidades opuestas a las que todo separa: la sensibilidad, el modo de vida, la ética, las relaciones con la naturaleza, El Estado, la patria, el poder, el trabajo, la historia y las aspiraciones. Una de ellas, minoritaria, florece en la prosperidad; la otra, mayoritaria está destinada a la muerte lenta y al aislamiento» ${ }^{4}$.

Dadas estas circunstancias, no es extraño que lo que se conoce como «Revuelta del Sur», en tanto que alternativa a la modernización occidental, podría verse bajo el signo del comunitarismo y la defensa de lo inalienable. Ello comportaría primar la dimensión de la solidaridad como ya advirtiera Tonnies en Comunidad y Sociedad, y posteriormente, Polanyi en la Gran Transformación ${ }^{5}$.

Es en este contexto, en el que se pueden contemplar importantes fracturas sociales en los procesos modernizadores llevados a cabo en las sociedades musulmanas de nuestros días, en el que vamos a examinar la emergencia de los movimientos islamistas, que, en tanto que ideologías de sustitución, tratan de saldar cuentas con todos los fracasos acumulados por las ideologías modernistas, tanto las reformistas como las nacionalistas y socialistas. 
El comunitarismo radical: el fundamentalismo islámico

Sentadas estas bases, nos aproximaremos al problema islamista abordándolo primero desde su envoltura más externa, es decir, aquella más visible a la opinión pública occidental que considera al islamismo político como la amenaza que ha venido a sustituir a la Unión Soviética. Tras este primer análisis, examinaremos, como si se tratara de un juego de muñecas rusas, una segunda capa constituida por los factores que han contribuido, o al menos favorecido, a la emergencia de estos movimientos en el mundo islámico, para en una tercera parte, dedicar nuestra atención al examen de los orígenes y fuentes intelectuales del fundamentalismo musulmán.

\section{La amenaza islámica como construcción mental}

Para todos los que hemos vivido una gran parte de nuestra existencia bajo el impacto de la «guerra fría», en definitiva, bajo la amenaza del choque nuclear entre las dos grandes superpotencias del siglo XX: Estados Unidos y la Unión Soviética, no ha dejado de ser frustrante que apenas un año después del agotamiento de esta situación por la disolución del imperio soviético, nuestro mundo se haya instalado en un nuevo paradigma de enfrentamiento, o al menos, parece como si quisiera hacerlo, que no sería otro que el constituido por la amenaza que el mundo islámico representaría para nuestra vida colectiva.

Ciertamente, el mundo islámico, al finalizar este siglo XX, contará con unos mil millones de creyentes en continua expansión, creciendo a un ritmo anual cercano al 3\%, y si a esto añadimos la memoria secular de enfrentamientos entre el Occidente, y aún el Oriente cristianos, y el Islam, las bases para fundamentar esta visión estarían servidas.

Y sin embargo, es evidente que si analizamos, hoy por hoy la fuerza militar, incluidas las posibilidades logísticas, de aquello que globalmente se conoce como amenaza islámica, sin minusvalorar su potencial y sus recientes avances en materia nuclear, esta pretendida amenaza queda disminuida hasta tal punto, que cualquier comparación con la situación precedente, protagonizada por la confrontación USA-URSS, nos hace ver con claridad su falta de consistencia.

Entonces, ¿cuál es la explicación de que los más significativos «depósitos de pensamiento» occidentales den por bueno este análisis? Quizás haya que empezar recordando que una de las características del pensamiento occidental en la época moderna, consiste en la tendencia a identificar lo pensado con lo realmente existente. También es propio de la modernidad, el intento de reconducir lo real hacia objetos de fácil asimi- 
lación; hacia «ideas claras y distintas» como quería Descartes. Sin embargo, como afirma un autor político de nuestros días: «Lo que es uno en la teoría se revela infinitamente múltiple en la realidad ${ }^{6}$. Algunos años antes uno de nuestros filósofos menos conocidos, hablando también de la época moderna decía: «La realidad se refiere a nosotros con amplitudes tales que rebasa con mucho las fronteras del pensamiento claro y distinto»? ${ }^{7}$.

En consecuencia ya podemos extraer una primera conclusión de carácter apriorístico; la aplicación de un enfoque de esta naturaleza a las relaciones entre el mundo occidental y el islámico corre el riesgo de producir grandes distorsiones cuyas consecuencias, al final, podrían ser pagadas por los pueblos y las personas atrapadas en estas mallas intelectuales.

Si el mundo musulmán está corriendo el riesgo en nuestros días, de mirar a Occidente con la "mirada mutilada" ${ }^{8}$, el mundo occidental parejamente, también corre el riesgo de mirar al mundo islámico desde una perspectiva unidimensional que, obviando las múltiples divisiones étnicas, religiosas, económicas, culturales y aún ideológicas existentes en el mismo, permite que nos forjemos una representación amenazante bajo el síndrome de una inminente «intifada colectiva». Y es que una de las características del pensamiento occidental, todavía en nuestros días, es la disyunción, la necesidad de interpretar las realidades de la vida en términos de identidad-oposición, lo que se traduce, cuando se trata de las relaciones entre pueblos de culturas diferentes, en un etnocentrismo estimulado durante la modernidad por la idea de la «perspectiva única y la contraposición entre sujeto y objeto» ${ }^{9}$. No obstante, hay que añadir que desde principios del siglo XX estamos asistiendo a un cambio epistemológico que postula la afirmación de lo diferente y complementario, lo que implica la «recuperación del conocimiento basado en la simpatía y en la connaturalidad con lo que se desea conocer». De esta manera la tesis de la complementariedad resultará, a la postre, clave para interpretar la realidad del siglo XX.

Este cambio de paradigma debería suponer el comienzo de la superación de las diferentes disyuntivas entre las que se ha movido el pensamiento moderno. Esto es lo que también debería ocurrir entre Occidente y el mundo islámico como aspecto destacado de las relaciones Norte-Sur. No parece ser éste, sin embargo, el punto de vista de los que: «buscan nuevas demonizaciones y las encuentran en una amenaza islámica a la civilización occidental o en un próximo choque de civilizaciones» ${ }^{10}$.

En esta misma línea José $\mathrm{M}^{\mathrm{a}}$ Tortosa ${ }^{11}$ afirma que: «la representación occidental del mundo islámico está sesgada y condicionada por una serie 
El comunitarismo radical: el fundamentalismo islámico

de estereotipos negativos que la identifican con el fanatismo, el terrorismo y el peligro de invasión». Según este autor intervendrían en esta perspectiva una serie de políticas de «construcción del enemigo» cuyo efecto serviría para aumentar la cohesión interna de los grupos. Así la acentuación de las diferencias y la construcción de una imagen negativa de la sociedad islámica facilitaría en la Unión Europea la construcción de una identidad común entre sus diferentes Estados, mientras que en E.E.U.U. el Islam vendría a sustituir al antiguo enemigo soviético. No obstante Tortosa concede una corta vigencia a este «mythomoteur», tanto desde USA, donde el poder emergente sería China, como desde la U.E., en donde esta construcción vendría además a complicarse mucho por la fuerte presencia del Islam dentro de la Unión (turcos en Alemania, argelinos en Francia, paquistaníes en el Reino Unido).

A pesar de todo lo que hemos venido exponiendo, pecaríamos de parcialidad si no incorporamos a este análisis introductorio algunos elementos que desde el lado musulmán refuerzan los aspectos negativos de estas construcciones mentales. Así y como afirma Cesar Vidal ${ }^{12}$ : «a diferencia del Cristianismo, incluso del Budismo, - la guerra no es un distanciamiento de la enseñanza inicial, sino un instrumento propugnado (por el Islam) para reducir el cosmos y someter en todo a judíos y cristianos. En los siglos posteriores a la muerte de Mahoma, el Islam vivió su expansión como una confirmación de la veracidad de sus enseñanzas. De la misma manera, cualquier intento de respuesta - desde las Cruzadas a la Guerra del Golfo, pasando por la lucha contra el Estado de Israel o el reciente conflicto de Daguestán, ha provocado un profundo resentimiento no sólo por lo que implicaba de ataque o reacción extranjeros sino también porque significaba el retroceso en el avance hacia la meta final de sumisión de todo el orbe al Islam».

\section{Factores socio-económicos que explican el Fundamentalismo Islámico}

Una vez dibujado el marco en el que ha hecho su aparición este nuevo fenómeno socio-político, es preciso corregir el enfoque, aumentando nuestro nivel de aproximación, para poder distinguir, más claramente, en qué consiste lo que con marcado carácter generalizador ha venido a denominarse Fundamentalismo Islámico.

La primera sorpresa con la que nos encontramos es que la propia voz con la que los occidentales designamos este conjunto de corrientes que han surgido en el mundo islámico, no sea una palabra de uso común en 
ese espacio cultural sino más bien una palabra importada: un préstamo cultural. Esta situación refuerza la opinión con la que iniciábamos este artículo: la inferencia que los distintos aparatos ideológicos y políticos del mundo occidental han tenido en la consideración de estos grupos político-religiosos.

En efecto, el Fundamentalismo, como es de sobra conocido, es un movimiento de reforma dentro del Cristianismo de principios del s. XX, cuya denominación es acuñada por teólogos liberales de esa época, opuestos a lo que esta tendencia significaba y que, por tanto, denota ya un cierto sabor peyorativo, cuando no ciertamente acusatorio. Por todo lo anterior, algunos autores como Randal K. James prefieren utilizar el término «revivalist» incluyendo en esta palabra, que podría traducirse por «restauracionismo", cuatro tipos de personalidades: tradicionalistas, modernistas, fundamentalistas y pragmáticos. El término «islamista» quizás sea más adecuado, en cuanto con él nos referimos a quienes: "pretenden incrementar el papel del Islam en la sociedad y en la política, generalmente con la idea de construir un Estado islámico» ${ }^{13}$.

Se inaugura de esta manera, y aproximadamente desde finales de los años sesenta, un nuevo debate que desde una perspectiva, pretendidamente, externa a Occidente podría ejemplificarse en el «choque de civilizaciones» de Huntington; y desde una óptica más interior, es decir alojada en el seno del Occidente secularizado de nuestros días, podría describirse como un debate entre: "un comunitarismo radicalizado y un laicismo amenazado» ${ }^{14}$. Así quizás pueda explicarse que, para muchos, el fin de la U.R.S.S. haya creado, especialmente a los Estados Unidos, más problemas que los que aparentemente resolvía su disolución. Y también es explicable que por una cierta inercia mental, muy acusada en el espacio social y político, el Islam pudiera ser puesto en lugar del comunismo, con todos los «tics» mentales que tal sustitución encarnaba y el complejo Libia-Irán-Irak en el lugar de la U.R.S.S.

No obstante, esta confrontación entre un comunitarismo radicalizado de base religiosa y un laicismo amenazado, solo es medianamente comprensible a finales del s. XX, si, como afirmara ya en 1985, Fernández Carvajal, no se hubiera producido «la fosilización del mito marxista, caído en la trampa del incumplimiento de sus promesas mesiánicas, lo que habría introducido en el mundo una oportunidad y un riesgo para la Religión: venir ella por vías más o menos directas a ocupar el hueco de la que a lo largo del siglo XX ha sido la más profunda ideología revolucionaria» ${ }^{15}$. Más adelante ${ }^{16}$ añadía: «en principio se-trata de la recuperación de una fuente de estímulos sociales que parecía extinta o casi extinta. Tal recuperación no tiene nada de extraño. La experiencia de «lo sacro» es de- 
masiado poderosa para quedar confinada dentro de estrictos límites individuales y rituales; lo sorprendente sería, más bien, su relativo estiaje a lo largo de los últimos cincuenta años de la historia de la humanidad».

Como confirmando este diagnóstico unos años más tarde, en 1991, lanzaba su «Revancha de Dios», Gilles Kepel y en ella ${ }^{17}$ se contienen afirmaciones como las siguientes: «daba la impresión de que a partir de la Segunda Guerra Mundial, el dominio público había conquistado una autonomía definitiva respecto de la religión, resultado éste de un proceso cuyos propulsores fueron los filósofos de la Ilustración. La religión veía restringirse su influencia a la esfera privada o familiar, y ya no parecía inspirar el orden de la sociedad sino de modo indirecto, como un vestigio del pasado ...», «es el conjunto de este proceso lo que hacia 1975 empieza a revertirse ya que surge un nuevo discurso que a través de múltiples expresiones propone la superación de una modernidad fallida a la que atribuye los fracasos y las frustraciones provenientes del alejamiento de Dios». En esta misma línea, o, al menos, haciéndose eco de parecidas preocupaciones, Eugenio Trías nos decía hace tres años que: «si hay un tema relevante en este fin de milenio, este es, sin duda, el religioso» y añadía: «es más, el final de la «Guerra Fría», parece sustituir el registro ideológico como lugar en donde se articulan las convicciones y los conflictos por el registro religioso» ${ }^{18}$.

Con todo lo anterior, creo que hemos bajado un segundo peldaño que nos aproxima a un objeto que es a la vez político y religioso, pero aún hemos de movernos hacia un tercer peldaño que nos sitúe ya en el centro del islamismo y en los factores de su desarrollo. Nos referimos, obviamente, al problema de la identidad, que si es sentido en nuestros días como preocupación global, todavía tiene un énfasis mayor en el mundo musulmán. Y es que como afirma Rafael Puyol: «dos dinámicas actúan sobre nuestro mundo a las puertas del tercer milenio, la de fisión con su fuerza de fractura que ha roto imperios y países y debilitado estados en todo el mundo y la de fusión que, con la misma energía, estimula la asociación y la integración de espacios comerciales y políticos» ${ }^{19}$.

El problema de la identidad en el mundo musulmán es el principal o primer factor en el que se orientan estos movimientos. ¿Por qué? Además del factor general al que acabamos de aludir, la historia de los pueblos islámicos nos aclara una parte importante de este problema. En síntesis podemos decir que como continuación de una edad de esplendor, el mundo árabe cae en una serie ininterrumpida de derrotas y de crisis: Las Cruzadas, el Imperio Otomano y finalmente la etapa colonial de los poderes occidentales. Incluso en la etapa postcolonial, el mundo islámico arrastra un fuerte sentimiento de inferioridad y de pérdida al comparar- 
se con el rico y avanzado mundo occidental. Y aunque el movimiento Panárabe de principios del siglo XX supuso una oportunidad para corregir esta situación, pronto se mostró impotente ante la falta de unidad de este mundo. La quiebra de los gobiernos secularizados y las derrotas de los ejércitos árabes ante el pequeño pero occidentalizado Estado de Israel no han hecho más que acentuar este sentimiento de impotencia. En contrapartida, una mirada a su pasado, más o menos mitificado, permite a los musulmanes contemplar una «Edad de Oro» bajo el imperio de la ley islámica. Sea o no verdadero este relato, estamos ante lo que ha proporcionado al islamismo una especial capacidad de convocatoria en un mundo donde proliferan las crisis de legitimidad de los gobiernos, un orgullo nacional muy bajo y la derrota de la identidad arábiga.

En estas circunstancias; «¿Por qué otra cosa podría sustituirse, hoy y en ese mundo, la pertenencia a una comunidad de creyentes? Lo grave, sin embargo, consiste en que esa pertenencia se presenta ahora como la pertenencia última, la menos efímera, la más arraigada, la única que puede satisfacer tantas necesidades esenciales del ser humano, y que no podría sustituirse de un modo duradero por otras pertenencias tradicionales a la nación, a la etnia, a la raza, ni siquiera a la clase ${ }^{20}$.

Esta situación ha hecho a aflorar en alguna medida en el mundo musulmán la nostalgia por la UMMA: la comunidad formada por todos los creyentes que es, indistintamente, religiosa, social y política. El término viene de UMM, madre en árabe, lo cual cuadra con su carácter amparador, nutricio, educativo. Un musulmán del Senegal, se siente miembro de la UMMA y hermano, por tanto, de otro musulmán del Turquestán chino o de Paupasia.. Ahora bien ocurre que la UMMA está social y políticamente desintegrada entre la variedad de Estados-nación que han surgido a partir de la independencia de las metrópolis coloniales. Pero, aún más lo está religiosamente por la escisión entre chiítas y sunnitas. Así que el musulmán se siente hoy, en cierta medida, desligado de su raíz, incómodo en el mundo ${ }^{21}$, y aunque estas divisiones tanto políticas como religiosas se mantienen, en la medida en que es posible distinguir entre un fundamentalismo de origen chiíta y otro de cuño sunnita, incluso movimientos fundamentalistas con impronta acusadamente nacionalista; lo que no cabe duda, es que los movimientos islamistas han resucitado con mayor o menor virulencia, según el país de que se trate, el proyecto utópico de refundación de la sociedad musulmana básica, así como la reconversión de todos los valores sociales a los principios de la UMMA musulmana. Su proyecto consistiría en la implantación de un contramodelo de modernización occidental, mediante la denuncia de los efectos perversos de ésta: aislamiento social, indivi- 
dualismo exacerbado, pasividad política, inflación burocrática, marginación y marginalidad ${ }^{22}$.

Estos problemas de identidad tienen inmediatamente su correlato político, al menos en términos de déficits de legitimidad, para los Estados surgidos de los procesos de descolonización y para sus elites dirigentes. En efecto, los Estados que se instauran en el mundo musulmán a fines de la década de los cincuenta y sesenta, nacen entre grandes entusiasmos colectivos y magníficas esperanzas, pero, salvo el caso marroquí probablemente, carecen, en cierta medida, de un apoyo base que se pudiera llamar «óntico» o sustancial. Es muy significativo, en este sentido, que las Constituciones de los nuevos Estados musulmanes, hagan siempre referencia a una suerte de comunidad transacional (La UMMA), políticamente vigente, que sirve como de asiento y soporte a las emergentes legitimidades y que suaviza un tanto lo que el Estado supone para esas sociedades de "préstamo cultural». Los primeros artículos de las nuevas Constituciones de estos países, sistemáticamente, hacen referencia a la «Gran nación árabe» o al Maghreb, lo que además de convertir, de facto, al Estado en algo transitorio y vicario, ha permitido acuñar la expresión de «Nación a dos niveles» como elemento caracterizador de estos sistemas políticos ${ }^{23}$.

Acontecimientos que aún perduran en la memoria colectiva como la Guerra del Golfo y el prácticamente general grito de protesta de las masas musulmanas desde el Índico al Atlántico, permiten suponer que el «casus belli» inicial: «la violación de las fronteras de un estado soberano como era Kuwait», no era percibido con la misma gravedad en la mentalidad occidental que en el corazón del mundo musulmán, probablemente, aparte de razones históricas o sociales, por la falta de arraigo de la dimensión estatal en el alma colectiva islámica.

Dar cuenta de esta contradicción, existente en las sociedades musulmanas y especialmente sensible para la visión occidental, supone la necesidad de volver al estudio, en parte abandonado en algunos sectores de la Ciencia Política, de las consecuencias sociales y políticas que toda Religión supone para el ambiente en que se desenvuelve. En este sentido, una Ciencia Política que se limite al puro conocimiento de lo político en sus aspectos estrictamente teóricos, corre el riesgo de no poder explicar satisfactoriamente los complejos procesos sociales que nos ha tocado vivir y quizás, no pueda ayudar a resolver los graves problemas que, a no dudarlo, se van a presentar, de hecho ya lo están haciendo, a la entrada del nuevo milenio.

Un segundo factor que ha contribuido al incremento del islamismo, es la quiebra de las ideologías seculares, especialmente las vinculadas al 
mundo occidental. Al rebufo de la independencia postcolonial muchos países musulmanes intentaron, de manera superficial, imitar al evidentemente superior Occidente o la Unión Soviética tanto en sus formas de gobierno como en el sistema económico, con escasos resultados en el terreno industrial, agrícola o económico. Después de décadas de ver la caída de las ideologías occidentales muchos musulmanes creyeron que había pocas cosas valiosas dignas de ser aprendidas de Occidente fuera de la ciencia y de la tecnología. Estos musulmanes vieron en el Islam la base para crear una sociedad más justa y más próspera bajo el eslogan: «El Islam es la respuesta».

Un tercer factor ha sido la irrupción de la cultura occidental en los valores islámicos, lo que es denominado por Dekmejan: «modernización y choque cultural». Ello no significa como ya se ha advertido anteriormente que el Islamismo rechace la tecnología occidental, que se considera neutral, de lo que se trataría es de ponerla al servicio de los valores de la fe musulmana.

Un cuarto factor ha sido la pérdida de legitimidad de las élites gobernantes y de las instituciones en gran parte debido a la oposición de estas élites a abrir el proceso político a otros, con el resultado de tener que incrementar las medidas represivas cuando la oposición crece o simplemente despierta. Irónicamente al reprimir o eliminar a una oposición basada en ideologías seculares se ha venido a potenciar directamente, en muchos casos, a las fuerzas islámicas, entre otras razones, por ser las mezquitas el único espacio exento desde el que se podía potenciar una oposición al gobierno.

En todo caso, es preciso tener en cuenta que el problema de la soberanía política y la legitimidad de los gobernantes plantea «ab initio», graves problemas en el Islam. Un aspecto básico de la fe musulmana es el de la «soberanía de Dios» lo que desde la óptica de muchos pensadores del Islam, y especialmente para los iniciadores del pensamiento islamista, ${ }^{24}$ significa que Dios es el único Señor y Legislador. Por tanto la consideración de que puedan existir otras entidades soberanas o la aceptación de otros principios ideológicos de carácter opuesto al expuesto anteriormente, debe ser considerado como "Shir» (idolatría). Esto significa que el concepto de soberanía implica, antes de nada, la total dependencia de los hombres respecto de Dios. Lo que tiene su traducción en todos los órdenes de la vida política incluso en el campo legislativo, en cuanto que toda legislación debe conformarse con los principios generales de la Sharia. Por tanto, el legislador secular es realmente un mero intérprete de la Ley Divina.

En el campo gubernativo, la cuestión de quién gobierna se torna particularmente ambigua ya que el gobernante sólo puede permanecer legí- 


\section{El comunitarismo radical: el fundamentalismo islámico}

timamente en el poder en la medida en que observe la Sharia, puesto que se entiende que el pueblo ha delegado en el gobernante precisamente el poder que viene de Dios mientras observe y haga observar la Ley de Dios. Algunos autores hablan de «Teodemocracia» para referirse a los regímenes políticos que han salido o puedan salir al amparo de esta visión del Islam. En definitiva, se trataría de una suerte de regímenes basados en la soberanía popular que, a su vez, estaría limitada por la santidad de Dios. Estas ideas han tenido su concreción práctica, a partir sobre todo del establecimiento de la República Islámica de Irán, en la idea de la «Wilayat al-faqih» o "gobierno del jurisconsulto», que basándose en el principio ya esbozado de la soberanía divina, se combinaría con una mezcla de representación popular y de supervisión por los juristas islámicos. Un Jefe religioso debe estar situado en la cima del sistema, como exteriorización de este dominio de lo religioso sobre lo secular.

Se entiende entonces que la difusión de estos principios ha contribuido a incrementar la deslegitimación de unos gobernantes que en muchos casos solo podían apoyarse en su eficacia a la hora de evitar la «fitna» es decir el desorden, tan temido por las masas musulmanas.

Por último, e íntimamente relacionado con todo lo anterior, no podemos olvidar la quiebra del orden social y económico existente en muchos de estos países. El agotamiento del modelo de socialismo estatal, la bajada de los precios del petróleo que se produjo en los años ochenta y noventa y la ineficacia de las políticas agrícolas e industriales emprendidas, han impedido que muchos sectores de la población, especialmente jóvenes o agricultores emigrados a las grandes ciudades, hayan podido incorporarse a los sectores económicos más activos que han permanecido en manos de una elite íntimamente conectada con los complejos del poder político-económico.

El Islam político es básicamente un movimiento de jóvenes estudiantes y de «nuevas clases medias» de funcionarios, incluyendo oficiales del ejército. No se puede decir que sean movimientos ligados a los Ulemas tradicionales puesto que, en general, y salvo en Irán que, no lo olvidemos, se aparta del modelo más general, debido a su chiísmo, estos movimientos son bastante hostiles al islamismo establecido.

La deficiencia de los sistemas educativos, caros y no directamente conectados con el mercado laboral, y la promesa incumplida de urbanización que ha llevado a individuos y familias emigradas del campo a la ciudad, a formas de vida donde prevalece la vulnerabilidad moral, el anonimato, el hacinamiento y el deplorable estado de las viviendas, son una inagotable fuente de frustraciones convertidas en caldos de cultivo propicios al radicalismo social y político. 
Como muestra empírica de lo que venimos diciendo presentamos unas tablas demostrativas de la fundamentación social de los integrantes de estos movimientos. Para ello nos hemos basado en los datos extraídos de los archivos judiciales egipcios que distribuyen por edad y ocupación a miembros del Jihad (movimiento islamista) acusados ante los tribunales.

\begin{tabular}{|c|c|c|}
\hline OCUPACIÓN & NÚMERO & $\%$ \\
\hline Estudiantes & 123 & 43.90 \\
\hline Trabajadores & 41 & 14.60 \\
\hline Profesionales & 35 & 12.50 \\
\hline Desempleados & 30 & 10.70 \\
\hline Comerciantes & 16 & 5.70 \\
\hline Funcionarios & 15 & 5.40 \\
\hline Policías y Militares & 14 & 5.00 \\
\hline Agricultores & 6 & 2.20 \\
\hline 280 & 100 & \\
\hline
\end{tabular}

Fuente: Jumaiva Nimatalla. $1998{ }^{26}$

\begin{tabular}{|c|c|c|}
\hline EDAD & NÚMERO & $\%$ \\
\hline 20 años & 49 & 17.50 \\
\hline $21-30$ años & 196 & 70.00 \\
\hline $31-40$ años & 30 & 10.70 \\
\hline+40 años & 5 & 1.80 \\
\hline 280 & 100 & \\
\hline
\end{tabular}

Fuente: Ibidem 
timamente en el poder en la medida en que observe la Sharia, puesto que se entiende que el pueblo ha delegado en el gobernante precisamente el poder que viene de Dios mientras observe y haga observar la Ley de Dios. Algunos autores hablan de «Teodemocracia» para referirse a los regímenes políticos que han salido o puedan salir al amparo de esta visión del Islam. En definitiva, se trataría de una suerte de regímenes basados en la soberanía popular que, a su vez, estaría limitada por la santidad de Dios. Estas ideas han tenido su concreción práctica, a partir sobre todo del establecimiento de la República Islámica de Irán, en la idea de la «Wilayat al-faqih» o "gobierno del jurisconsulto», que basándose en el principio ya esbozado de la soberanía divina, se combinaría con una mezcla de representación popular y de supervisión por los juristas islámicos. Un Jefe religioso debe estar situado en la cima del sistema, como exteriorización de este dominio de lo religioso sobre lo secular.

Se entiende entonces que la difusión de estos principios ha contribuido a incrementar la deslegitimación de unos gobernantes que en muchos casos solo podían apoyarse en su eficacia a la hora de evitar la «fitna» es decir el desorden, tan temido por las masas musulmanas.

Por último, e íntimamente relacionado con todo lo anterior, no podemos olvidar la quiebra del orden social y económico existente en muchos de estos países. El agotamiento del modelo de socialismo estatal, la bajada de los precios del petróleo que se produjo en los años ochenta y noventa y la ineficacia de las políticas agrícolas e industriales emprendidas, han impedido que muchos sectores de la población, especialmente jóvenes o agricultores emigrados a las grandes ciudades, hayan podido incorporarse a los sectores económicos más activos que han permanecido en manos de una elite íntimamente conectada con los complejos del poder político-económico.

El Islam político es básicamente un movimiento de jóvenes estudiantes y de «nuevas clases medias» de funcionarios, incluyendo oficiales del ejército. No se puede decir que sean movimientos ligados a los Ulemas tradicionales puesto que, en general, y salvo en Irán que, no lo olvidemos, se aparta del modelo más general, debido a su chiísmo, estos movimientos son bastante hostiles al islamismo establecido.

La deficiencia de los sistemas educativos, caros y no directamente conectados con el mercado laboral, y la promesa incumplida de urbanización que ha llevado a individuos y familias emigradas del campo a la ciudad, a formas de vida donde prevalece la vulnerabilidad moral, el anonimato, el hacinamiento y el deplorable estado de las viviendas, son una inagotable fuente de frustraciones convertidas en caldos de cultivo propicios al radicalismo social y político. 
de estas áreas ha oscilado entre el 10 y el $20 \%$ en la década de los ochenta. La mayoría de estas áreas ha presenciado disturbios de carácter religioso y allí reside un porcentaje proporcionalmente alto de militantes islámicos.

La mayoría del crecimiento urbano que afecta a estos barrios ha sido esporádico y accidental, basado principalmente en viviendas irregulares y servicios e instalaciones sin planificar. El 56\% de las casas están construidas sobre terrenos no registrados en la capital egipcia, el $38 \%$ consiste en edificios no registrados y el $73 \%$ de las casas fueron construidas en la década de los setenta y ochenta sin permiso de construcción. En cuanto a instalaciones, de un 35 a un $43 \%$ de los edificios no tenían agua corriente, entre un $29-44 \%$ no estaban conectados a la red de alcantarillado, un 10-12\% no contaban con suministro eléctrico.

Hacia esta época, y aunque la tendencia ha decrecido, la gente empezó a residir en los cementerios aunque dicha práctica esté prohibida por la tradición islámica. Paradójicamente la vida del cementerio no es tan mala, ya que la mayoría de las tumbas ocupadas eran espaciosas y estaban sólidamente construidas en torno a unos patios y, normalmente tenían una entrada, de dos a cuatro habitaciones, una cocina y un lavabo, así como un pequeño jardín.

Dos tercios de los habitantes de estos barrios urbanos esporádicos $(67,20 \%)$ son inmigrantes que, en su mayoría, provienen del Alto Egipto (Asijut, Suhag, Anina y Minya). Ello ha hecho que el Alto Egipcio y la periferia de El Cairo se encuentren real y simbólicamente unidos por un mismo proceso: el de la emigración ${ }^{27}$ que ha dado lugar a una mezcla muy heterogénea de influencias rurales y urbanas, un entorno capaz de nutrir al extremismo intelectual y religioso. De estos barrios «esporádicos» han surgido la mayoría de los militantes islamistas.

¿Puede el Islam resolver estos problemas? Ya adelantamos que, como la denominada revolución islámica en Irán está demostrando, los movimientos islamistas se muestran bastante limitados a la hora de cambiar el mundo de hoy o incluso de comprenderlo. Se podría decir como afirma Ayubi $^{28}$ que el Islamismo representa una «huida hacia arriba» que no es más que trasunto de su incapacidad para poder cambiar el orden social y todo ello en un tono más populista-corporativista que propiamente socialista. ¿Pero quiénes son los islamistas?.

\section{Orígenes y fuentes del Movimiento islamista}

Los movimientos islamistas representan hoy el cuestionamiento más temible para el poder establecido en el mundo musulmán. Treinta años 


\section{El comunitarismo radical: el fundamentalismo islámico}

después de la independencia, las nuevas generaciones - aproximadamente el $60 \%$ de la población - no aceptan ya los proyectos sociales del Estado modernizador surgido de la descolonización ${ }^{29}$.

Sin embargo intelectualmente el islamismo viene de más lejos, porque entre sus fuentes hay que recordar a los Hermanos Musulmanes fundados en 1929 en Ismailia por el egipcio Hassan al Banna. A partir de los años treinta empieza a notarse su influencia que, no obstante, se vio limitada por la denominada revolución de los «oficiales libres» de julio de 1952, que dio el poder a Naguib primero e inmediatamente a Nasser quien supo poner en marcha mitos movilizadores como el de la «nación árabe», una suerte de panarabismo sustentado en el imaginario colectivo de la UMMA.

Habrá que esperar a la derrota frente a Israel en 1967 para ver como los gobiernos árabes empezaron a servirse de las corrientes religiosas como ariete para luchar en las Universidades contra las influencias marxistas. No obstante, quizás haya que adelantar que, sin la revolución iraní de 1979, los movimientos islamistas posiblemente hubieran continuado durante mucho tiempo como conjunto de tendencias activistas pero minoritarias.

El islamismo magrebí comparte también la herencia de los Hermanos Musulmanes. Algunos de sus líderes como Ghanouchi recibieron formación en Egipto y Siria, sin embargo hay que resaltar que, probablemente, la sociedad magrebí que mejor ha sabido controlar, hasta el momento, al islamismo, ha sido la marroquí, en la medida en que la monarquía alauita está directamente implicada en la fe musulmana dado el carácter de Emir al-Muminin de su Rey o Comendador de los creyentes, y que no ha permitido, o, al menos, ha obstaculizado que los movimientos religiosos de este carácter se hagan cargo de la juventud marroquíi ${ }^{30}$.

Si Hassan al-Banna funda en 1929 los Hermanos Musulmanes en la estela del Wahhabismo de Arabia ${ }^{31}$. Una década más tarde, Abú a'lá Maududi funda un movimiento similar en la India. Ambos movimientos están muy influenciados según Khalid ${ }^{32}$ por los partidos totalitarios que en los años veinte y treinta se desarrollan en Europa. Hay que recordar que el liberalismo se encontraba entonces sumido en una profunda crisis y ambos autores admiraban la disciplina y el dinamismo de los fascistas. Además, desde su lejana perspectiva, el fascismo parecía un movimiento renovador que, además, estaba en oposición a las potencias coloniales: Francia y G. Bretaña. No obstante, debemos señalar que el conocimiento del fascismo era superficial y sería injusto suponer que estos pensadores comprendieran todas las implicaciones de este nuevo fenómeno en el continente europeo. Es sabido que Iqbal, fallecido en 1938 y uno de los más conocidos poetas y filósofos paquistaníes, autor de orientación fun- 
damentalista, visitó a Mussolini en Roma y que Mashriqui, otro activista indio, tuvo una entrevista con Hitler.

El último islamista original sería Khomeini que a su vez se habría inspirado en el egipcio y sunita Sayyid Qutb y en Mawdudi, quienes, a su vez, se habrían inspirado en fuentes occidentales aunque luego reaccionaran contra ellas. Es este sentido, y aunque los islamistas se presentan a sí mismos como firmes creyentes en el Islam, sin embargo elaboran y a veces se basan en una noción de supremacía del Islam que, en la práctica, es muy cercana a la del «Superhombre nitzcheano» que debe dominar a la humanidad. Iqbal buscó islamizar a su admirado Nietzsche proyectando en su inflamable poesía iraní y urdú un «nuevo hombre musulmán» ${ }^{33}$.

No obstante esta pretensión de universalidad, lo cierto es que el radicalismo islamista se funda en algunos países en unos grupos o etnias a expensas de otras. Así los islamistas sudaneses están prácticamente reducidos a la fracción de población más arabizada. Por su parte, en Argelia los beréberes, que conforman el 25-30\% de la población, son opuestos al islamismo. En Paquistán el radicalismo islámico solo tiene éxito entre los «muhajirin» es decir los refugiados de la India en los años de la independencia, pero no obtiene prácticamente adeptos entre los nativos musulmanes del territorio paquistaní. En Irán se produce una virtual exclusión de las minorías sunitas e incluso los chiítas azeries están pobremente representados entre los islamistas. En Turquía, el islamismo solo se desarrolla entre los turcos étnicos, con escasos seguidores entre la minoría kurda. En otros países como Marruecos, los islamistas tienden a ser fuertes en regiones que tienen motivos de rencor frente a otras, como la zona norte de Marruecos que ha sido descuidada por Rabat.

Sin embargo, el problema islamista, a pesar de sus fundamentos socio-económicos, no se reveló en toda su crudeza mientras que fue utilizado como bastión de resistencia frente a la U.R.S.S. y, por tanto, estimulado más o menos directamente, al menos en su versión Wahhabita por los Estados Unidos y los gobiernos afines en los países musulmanes ${ }^{34}$. Hoy ya se puede afirmar, con la perspectiva que produce el paso del tiempo, que el golpe de gracia a las ideologías modernizadoras y la consiguiente oportunidad para el Islam político, se produce a partir de la Revolución iraní de 1979, en cuanto supuso el primer movimiento político importante de alejamiento de los ideales políticos occidentales en el s. XX. Hasta Khomeini los líderes de todos los grandes movimientos sociales en el mundo musulmán defendían objetivos que, en gran parte, provenían del pensamiento occidental, ya fuese liberal, marxista o fascista. Los principales líderes no occidentales desde Kemal Ataturk en la Tur- 
El comunitarismo radical: el fundamentalismo islámico

quía de los años veinte a Ben Bella en la Argelia de los sesenta, pasando por Sukarno en Indonesia, siempre habían propuesto a sus países metas familiares a Occidente en sus aspectos sociales, económicos y políticos, lo que ayudó a consolidar la idea de la «imitación a Occidente» ${ }^{35}$.

En todo caso, los movimientos islamistas aunque opuestos a las ideologías modernizadoras no dejan de ser hijos, todo lo espúreos que se quiera, de este mismo modelo. Así Oliver Roy ${ }^{36}$ manifiesta que mientras las guerrillas de inspiración marxista solían ser campesinas, los movimientos islamistas son urbanos y por tanto sociológicamente más modernos. El prototipo de un «cuadro» perteneciente a un grupo islamista sería el siguiente: "Ingeniero, nacido en torno a los años cincuenta en un medio urbano e hijo de padres urbanizados recientemente». Más aún la élite del islamismo de los años noventa incluso ha prolongado sus estudios universitarios en Occidente. Así Velayat, antiguo ministro de A.A.E.E. iraní, es pediatra formado en USA. Navabi, ex ministro iraní de industria es un ingeniero formado también en USA. En Turquía una cuarta parte de los cuadros del partido islamista de salvación nacional eran ingenieros en los años setenta. En Marruecos, Abdesalam Jassine es inspector de educación nacional para la enseñanza en lengua francesa. En Argelia, el portavoz del Fis a principios de los noventa, Abdelkader Hachari es ingeniero de petróleos ${ }^{37}$. Y aunque sea cierto que frecuentemente se ha asociado la emergencia de los movimientos islamistas con procesos de urbanización y/o modernización frustrados, crecimiento de la marginación y consecución de los procesos de ajuste estructural del F.M.I. o del Banco Mundial, no se puede olvidar la buena salud social y profesional de amplios sectores del movimiento islamista y más concretamente de los Hermanos Musulmanes egipcios o jordanos bien representados en las profesiones liberales así como en el ala tecnocrática del Fis argelino ${ }^{38}$.

Ahondando un poco más en las fuentes del islamismo radical podemos encontrar raíces de esta actitud en el impacto producido en el Islam por la «filosofía de las Luces» y el movimiento industrializador europeo. De este choque brotó en el s. XIX la «Nahda» (Renacimiento) básicamente animado por intelectuales egipcios y sirio-libaneses. Este «Renacimiento» engendrará dos ramas principales: el modernismo desarrollado por Tahtavi (1801-1873) que, influido por la Revolución francesa y Saint Simón, pondrá el acento en la patria y la segunda corriente, más fundamentalista protagonizada por Al-Afgani (1839-1905) que preconiza el retorno a las fuentes de la fe y la restauración de la grandeza de la UMMA, aún teniendo en cuenta las exigencias del mundo moderno.

En el siglo XX, las teorías de estos pensadores se incardinaron en los consiguientes movimientos políticos: El modernismo liberal estará en el 
origen del nacionalismo árabe ilustrado (partidos Baasistas de Siria e Irak y Nasserismo en Egipto). La corriente opuesta daría origen a los Hermanos Musulmanes causa inmediata del Fundamentalismo de nuestros días. Las dos ideologías en su evolución han mostrado ser competitivas entre sí y rivales como se demostró plasticamente en la guerra Irán-Irak que enfrentó a un régimen baasista (Irak) contra un régimen fundamentalista (Irán) ${ }^{39}$.

El fracaso de la corriente nacionalista ha dejado en un primer plano a la corriente rival que, sin embargo, no forma un frente monolítico, en contra de la opinión general ${ }^{40}$, sino que básicamente es posible distinguir dos ramas:

a) La revolucionaria, formada por seguidores del egipcio Sayyid Qutb, ajusticiado en 1966, que apela a la violencia para derribar los regímenes corrompidos y

b) Una segunda línea más gradualista que intenta el mismo fin pero no por medios violentos. El problema básico aquí es conciliar tradición y modernidad.

Como afirmara E. Gellner ${ }^{41}$, tanto en uno como en otro caso, el estrato más elevado del Islam parece haber vencido a la versión más inferior del mismo. El Estado moderno, a través de su centralización, ha socavado y desgastado a las tribus que eran el mercado natural de los santones. Estos mediadores profesionales, como la aristocracia francesa anterior a la Revolución, perdieron sus funciones mientras siguieron reclamando sus privilegios, con lo que pasaron a ser objeto de repudio popular. Esta es la esencia de la gran reforma que Occidente solo ha percibido en los últimos años bajo la sorprendente forma de fundamentalismo. En definitiva, las tribus ya no influyen en la política del Estado sino que han sido reemplazadas por redes de clientelismo político que permiten una atractiva autoidentificación a las masas atomizadas y desarraigadas. A esto debemos añadir que el nacionalismo político ha cumplido ya su ciclo en el Oriente Musulmán y allí donde no desaparece se trasunta en discurso religioso ${ }^{42}$.

Estas sociedades se encuentran, por tanto, ante la necesidad de reformular el «sui generis» contrato social, que, hasta épocas relativamente recientes, se encontraba vigente y que, básicamente, consistía en que los pueblos renunciaban a las libertades políticas y constitucionales, teóricamente ajenas al ámbito islámico, mientras que sus dirigentes se comprometían a proporcionarles un nivel de vida digno. De esta manera, el incumplimiento por parte de los gobiernos modernizadores de su parte 


\section{El comunitarismo radical: el fundamentalismo islámico}

del contrato ha proporcionado al fundamentalismo la fuerza que hoy tiene, dado que la mayoría de la población se encuentra excluida de los procesos políticos y económicos y se ve obligada a recurrir al Islam militante para reivindicar sus aspiraciones y expresar sus agravios ${ }^{43}$. Esta exclusión y el consiguiente vacío, ha sido hábilmente aprovechado por el islamismo político, tejiendo poco a poco un sistema alternativo de ayuda social, y encuadrando y movilizando a los marginados con sus promesas de cambio social. Simultáneamente, las carencias y la degradación del sistema escolar provocaron en su momento, al menos en Argelia, un trasvase de niños y adolescentes a improvisadas escuelas coránicas exentas de todo control por parte del poder oficial. El Islamismo en algunos países, como Argelia, se ha convertido en el común denominador identificatorio de todos los marginados ${ }^{44}$.

Ciertamente, nos dice Cruz Hernánde ${ }^{45}$, el integrismo es una utopía, pero la utopía es necesaria para los más jóvenes y para las minorías intelectuales como sucedió en Occidente. Pero, según este mismo autor, existe una diferencia fundamental: los movimientos Occidentales de protesta de los años sesenta y setenta y aún los de nuestros días como los verdes, operaron u operan sobre una retícula social que tiende a la permisividad y está radicalmente secularizada. En cambio, los jóvenes integristas islámicos se consideran íntegros, seguros e insecularizables pues, si lo fueran, pensarían que habían perdido su integridad social.

\section{Notas}

1 Ortega Andrés. Blair, el comunitario. El País 14-IV-97.

2 Gonzalo Eduard. El comunitarismo como crítica al liberalismo en ideológias y movimientos políticos contemporáneos. Editorial Tecnos. Madrid 1999. p. 429.

3 NAval Concepción y Sisón Alejo J. Los proyectos comunitaristas en América y en Europa. En este número sobre este mismo tema se puede consultar también Pérez Adán J. Socioeconomía y La salud Social. Editorial Trotta. 1997 y 1999.

4 Ghalioun Burham. Citado por Jesús Ballesteros en La Postmodernidad. Tecnos 1989. p. 126.

5 Ballesteros Jesús. Opus cit. p. 126.

6 EsPÓSITo Roberto. Confines de lo político. Trotta. Madrid 1996. p. 22.

7 García Llorente Manuel. El hecho extraordinario. Rialp. Madrid 1996. p. 125 y 126.

8 Shayegan Daryush. La mirada mutilada. Península. Barcelona 1990.

9 BAllesteros Jesús. Postmodernidad: decadencia o resistencia. Tecnos. Madrid 1989. p. 120.

10 Esposito John L.The islamic threat Myt or Reality? Oxford University Press. N. York. $2^{\text {a }}$ edition 1995. pp. 188 y s.s. 
11 Tortosa José María. El Islam ¿enemigo de Occidente? Papers, 57. Universidad Autónoma de Barcelona. Servei de Publicacions. 1999. p. 75-88.

12 VIDAL Cesar. «Combatid hasta que estén por debajo». El Mundo. 23 de septiembre de 1999. p. 4.

13 RANDAL K. James. Understanding Islamist in the middle EAST and North Africa Institute for National Strategis studies. 1996. Citado en Internet. www.ndu.edu/books lersa.html

14 SadiK Jalal AL-AzIM. Sur l'islam, la laicité et l'occident. Le Monde diplomatique.Septiembre 1999.

15 Fernández Carvajal R.Curso fundamental de Ciencia Política - 1986-1986. Departamento de Derecho Político. F. de Derecho. Universidad de Murcia. p. 128.

16 Ibídem. p. 129.

17 KePEL Gilles. La Revancha de Dios. Anaya. M. Muchnik. 1991. p. 13.

18 TRIAS Eugenio. Pensar la Religión. Ensayos / Destino. Barcelona 1996. p. 15 y 16.

19 PUYOL Rafael. La singularidad demográfica española. ABC. 25 de septiembre de1999. p. 3.

20 MAALOUf Amin. Identidades asesinas. Alianza Editorial. Madrid 1999. pp. 71 y s.s.

21 Muchas de estas reflexiones se deben al Profesor Fernández Carvajal quien en su Curso Fundamental de Ciencia Política supo adelantarse en la exposición de problemas que unos años más tarde se convertirían en cruciales para la comprensión de las cuestiones políticas y sociales de nuestra época. Vid. Curso Fundamental de Ciencia Política. Sección VI, Depto. de Derecho Político. Universidad de Murcia. Curso 1985-1986.

22 LAMCHICHI. Islam et contestation au Magreb. París. L’Harmatán 1989.

23 ABDEL MALECK. La pensé politique arabe contemporaine. Cit en Bernabé López García. Introducción a los Regímenes y Constituciones árabes. C.E.C. 1985. p. 23.

24 Véase en este sentido. GIUNCHI, Elisa. The political thought of ABUL A'LA MAWDUDI. Il Politico. Univ. de Pavía nº 2. 1994. pp. 347-375.

25 Ver en este sentido ChiBli Mallat. The renewal of Islamic Law; Muhamad Baqras-Sadr. Cambridge University Press. N. York 1993.

26 Jumaina Nimatallatanzim al-Jihad. Dar al-HURRIYA. El Cairo. 1988. pp. 142143. Citado por Nazih Ayubi. El Islam político. Biblioteca del Islam Contemporáneo $\mathrm{N}^{\circ} 3$. E. Bellaterra. Barcelona 1996. p. 229 y 230.

27 AYUBI NAZIH. Opus cit. pag 224 y s.s.

28 AYUBI NAZIH. Opus cit. p. 319.

29 Leveau Remy. Le sable et le turbau. L'avenir du Maghreb. Editions François BOURIN. París. 1993. p. 175 y 183.

30 LeVEAU Remy. Opus cit. p. 186

31 N. del Autor. El Wahhabismo es una corriente religiosa musulmana fundada por Wahhab (1703-1787) seguidor de la tendencia hanbalí, que pasa por ser la más rígida de las escuelas jurídicas del sunnismo.

32 DURAND K. İslamisme. Ideological connotations and current trends. Res Berichte $\mathrm{N}^{0}$ 127, märz 1992. Fiedrich-Ebert Stitfung p. 59 y s.s.

33 DuRAn Khalid Opus cit. pp. 59 y s.s.

34 Balta Paul. El fenómeno islamista. Claves de Razón Práctica. Octubre 1990, nº 6. p. 12 .

35 PIPEs Daniel. El Islam. Espasa Calpe. Madrid 1987. p. 19.

36 Roy Oliver. L'echée de l'Islam politique. Esprit / Senil. 1992. p. 18. 


\section{El comunitarismo radical: el fundamentalismo islámico}

37 Roy Olivier.Opus cit. p. 72.

38 BoRgAT François. El Islamismo cara a cara. Edicions Bellaterra. 1996. pp. 42 y S.S.

39 BaLta Paul. Le retour a la loi islamique. Etat des Religions. Paríss. 1977, p. 577.

40 Martínez Montalvez P. Fundamentalismo (s) islámico (s). Tribuna libre. El Mundo. 13-V-1995.

41 Gellner Ernest. La cultura política del Oriente próximo musulman. Claves de Razón Práctica. Nov. 1997. N 7 . En esta línea ver. Goytisolo Juan: Islam y Política. Cap. II. El País. 28-3-1994.

42 JAvaloyes José. La voz del Almuédano. ABC. 23-IX-96.

43 Menéndez del Valle Emilio. La integración del islamismo. El País. 24-I-1996.

44 Goytisolo Juan. Las razones del Fis. El País. 29-III-94.

45 Cruz Hernández Miguel. Historia del Pensamiento en el mundo islámico. Alianza. Universidad. Madrid 1996. pp. 816 y s.s.

\section{Bibliografía}

ABdel MaLeK La pensé politique arabe contemporaine. Cit en Bernabé López Garcia. Introducción a los regímenes y constituciones árabes. C.E.E. pag. 23. 1985.

AYUBI NAZIH El Islam político: Teorías, tradición y rupturas. Biblioteca del Islam contemporáneo. Barcelona. pp. 224 y s.s. 1996.

Balta P. Le retour a la loi islamique. Etat des Religions. París. p. 577. (1990). El fenómeno islamista. Claves de Razón Práctica. Octubre. $\mathrm{N}^{\circ}$ 6. p. 12.1977

BAllesteros J. Postmodernidad: Decadencia o resistencia. Tecnos. Madrid. pag. 120. 1989.

BORGAT, F. El Islamismo cara a cara. Edicions Bellaterra. pp. 42 y s.s. 1996.

Chibli MaLlat ). The revewald of islamic law: Muhamad Basq as-Sadr. Cambridge. University Press. N. York. 1993.

CRUZ HERNÁNDEZ M. Historia del pensamiento en el mundo islámico. Alianza Universidad. Madrid. pp. 816 y s.s. 1996.

DURAND K. Islamism. Ideological connotations. Problems of international cooperation. $\mathrm{N}^{\circ}$ 127. März. Heransgegeben von der F. Ebert-Stitfung. p. 59. 1992.

EsPósito R. Confines de lo político. Trotta. Madrid. p. 22. 1996.

EXPósito J. L. The islamic Treat. Myt or reality? Oxford. University Press. N. York. $2^{a}$ Edición. pp. 188 y s.s. 1995.

Fernández Carvajal R. Curso Fundamental de Ciencia Política 1985-86. Dpto. de Dcho. político. F. de Derecho. Universidad de Murcia. p. 128. 1985.

GHALIOUN BURHAN El islamismo como identidad politica. Fundación CIDOB. Afers Internationals $\mathrm{n}^{\circ} 36$. pp.59-76. 1997.

GarCía Morente M. El hecho extraordinario. Rialp. Madrid. pp. 125 y 126. 1996.

GeLlner E. La cultura Política del Oriente Próximo Musulmán. Claves de Razón Práctica. Nov. No 7. 1997.

GiUnchi E. The political Thought of ABULL A'LÀ MAUDUDI. Il Politico. No 2. Universidad de Pavía. pp. 347-375. 1994.

GONZALO E. El comunitarismo como crítica al liberalismo en ideologías y movimientos contemporáneos. Edit. Tecnos. Madrid. p. 429. 1999.

GoyTisolo J. Las razones del Fis. El País. 29-III-94. Islam y Política. El País. 28-III-94. 
1994.

JAVAlOYES J. La voz del Almuédano. ABC. 23-IX-96. 1996.

Jumaina N. Tanzim al Jihad. Dar al Hurriya. El Cairo. pp.142 y 143. 1988.

KePEL G. La revancha de Dios. Anaya. Muchnik. p. 13. 1991. 1999.

LAMCHICHI Islam et contestation au Maghreb. Paris. L'Harmatán. 1989.

Leveau R. Le sabre et le turbeau: l'avenir du Maghreb. Editions François Burin. París. pp. 175 y 183. 1993.

MAALOUF A. Identidades asesinas. Alianza Editorial. Madrid. p. 71 y s.s. 1999.

Martínez Montavez P. Fundamentalismo(s) Islámico(s). Tribuna Libre. El Mundo. 13V-95. 1995.

MenÉndeZ Del VAlle La integración del islamismo. El País. 24-I-96. 1996.

NAVAl C. y Sisón, Alejo Los proyectos comunitaristas en Europa y América.

ORTEGA A. Blair, el comunitario. El País 14-IV-97. 1997.

PIPES D. El Islam. Espasa Calpe. Madrid. p. 19. 1987.

PUYOL R. La singuladidad demográfica española. ABC. 25-IX-99. 1999.

RANDAL K. J. Understanding Islamist in the Middle East. Institute for National Strategie Studies. Cit. en Internet. www.ndu/edu/books/ersa.htlm. 1996.

SADIK JALAL AL-AzIm Sur l'Islam, la laicité et l'occident. Le Monde Diplomatique. Septembre. 1999

Shayegan D. La mirada mutilada. Península. Barcelona. 1990.

Tortosa Blasco J. M. El Islam. ¿enemigo de Occidente? Papers. N 57 . Universitat de Barcelona. Servei de Publicacions. pp. 79 y s.s. 1999.

TRIAS E. Pensar la Religión. Ensayos / Destino. Barcelona. pp. 15 y 16. 1996.

VIDAL C. "Combatid hasta que estén por debajo». El Mundo. 23-IX-99. 1999. 